"نشريه علوم زراعى ايران"

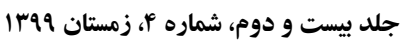

مقاله ئوهشى

اثر روش خاكىورزى، شيوه كاشت و ميزان كود نيتروزن بر خصوصيات زراعى و عملكرد دانه كلزا (Brassica napus L.)

Effect of tillage system, planting method and nitrogen fertilizer rate on agronomic charachteristics and seed yield of oilseed rape (Brassica napus L.) cv. Dalgan in Guilan, Iran

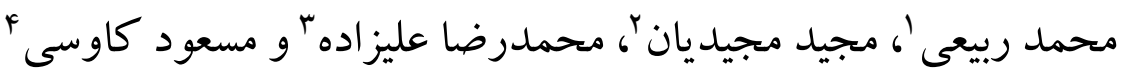

جكکبه

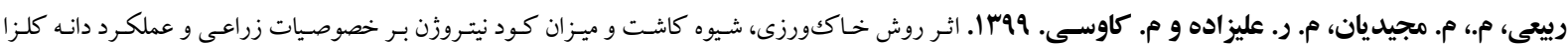
(Brassica napusL.)

بهمنظور بررسى اثر روش خاككورزى، شيوه كاشت و ميزان كود نيتروزن بر خصوصيات زراعى و عملكرد دانه كلزا رقم دلتَـان،

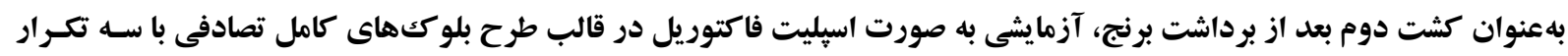

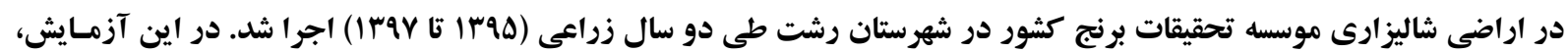

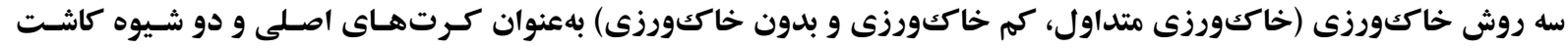

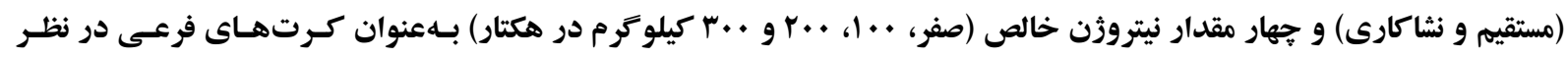

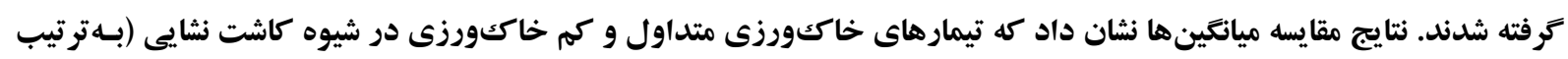

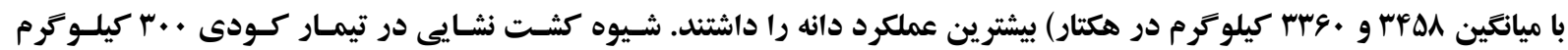

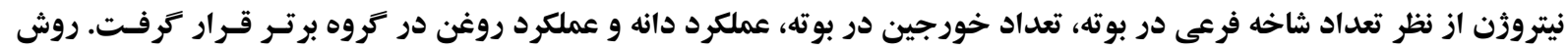

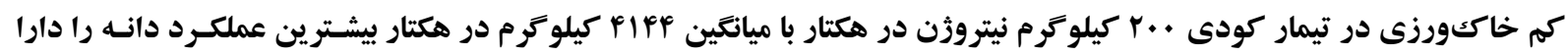

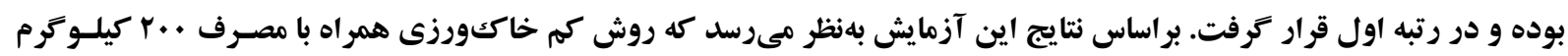

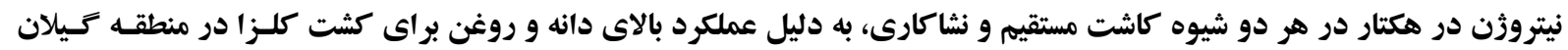
مناسبتر است.

وازههاى كليدى: كشت مستقيم، كثت نشايى، كلزا، كمخاكورزى و كود نيتروزن.

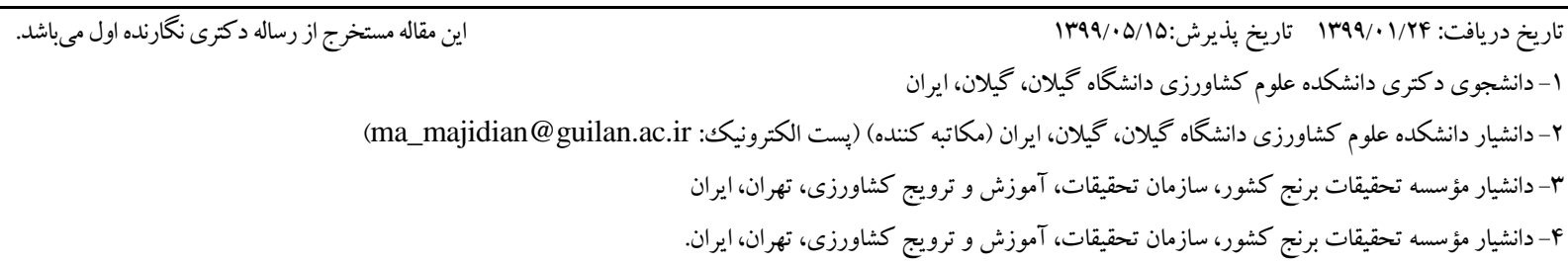


بدون شخم يا شخم حداقل، در حفاظت از آب و خاكك

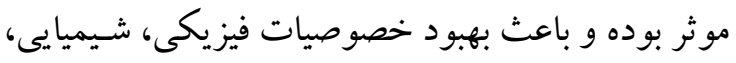

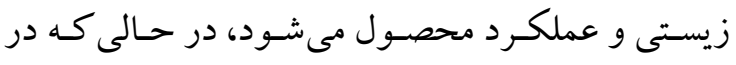

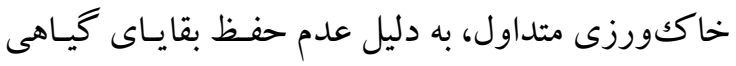

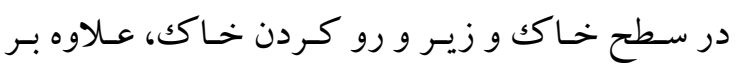
كاهش رطوبت خاكك، با تسريع اكسيداسيون مواد آلى، رونى

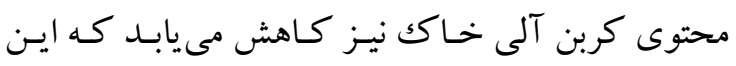
موضوع باعث كـاهش كيفيـت خصو صيات فيزيكى و ونى شيميايى خـاكك مسى شـود (Karlen et al., 2013). نتايج يكك آزمايش در خصوص ارزيابى اثر خـاككورزى بـر

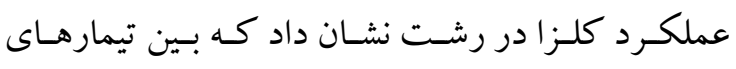

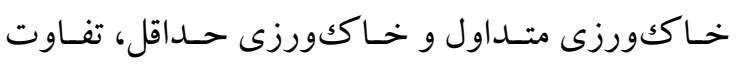
معنىدارى وجود نداشت، ولى تيمار بدون خـاككورزى

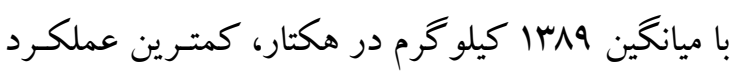
دانسه راداشــت (Alizadeh and Allameh, 2015). فولادىوند و همكاران (Fooladivand et al., 2009) نيـز

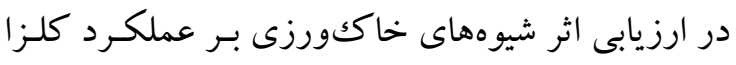
كزارش نمودند كه بالاترين ميزان عملكرد دانه از تيمـار

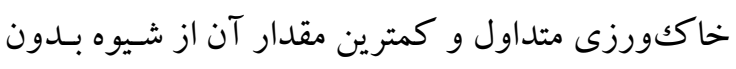

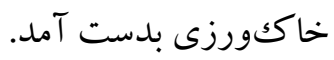
نيتروزن به دليل نقـش و اهميتى كـه در فر آينـدهاى

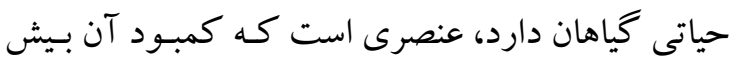

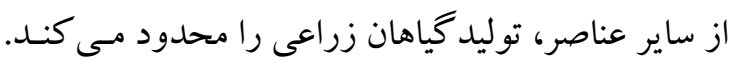

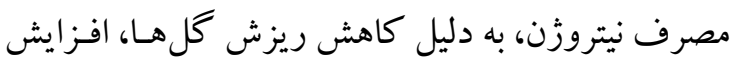

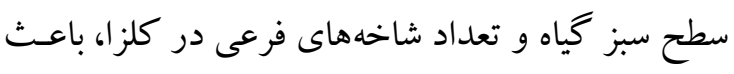

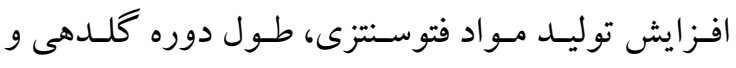

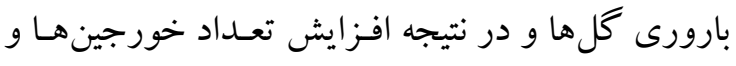

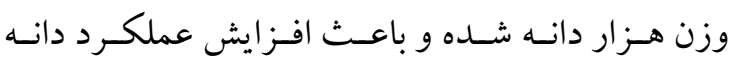

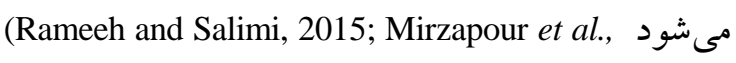
2014; Elewa et al., 2014) داده است كه با مصرف كود نيتـروزن، عملكـرد دانه و

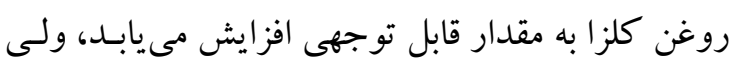

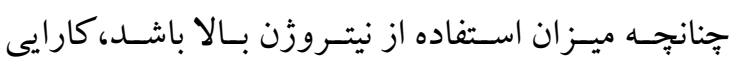

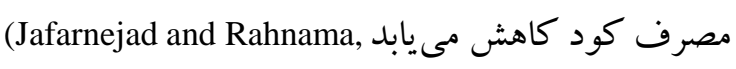

\section{مقدمه}

كلـزا (Brassica napus L.)، بعـد از سـويا و نخـل روغنى، سومين محصول زراعى مهم تأمين كننده روغن خوراكى در دنيا محسوب مى شود (FAOSTAT, 2017).

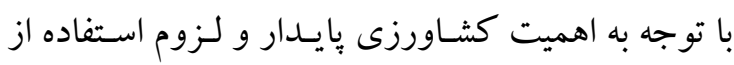

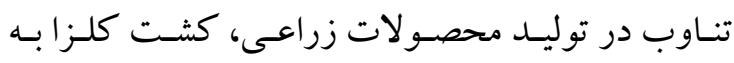

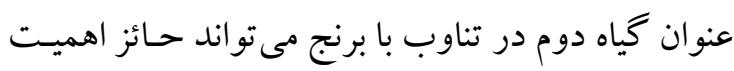

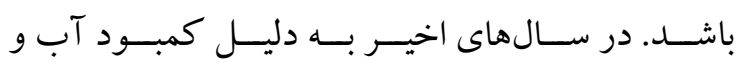

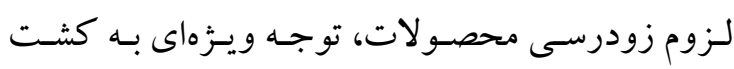

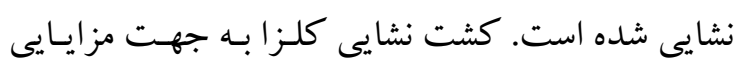

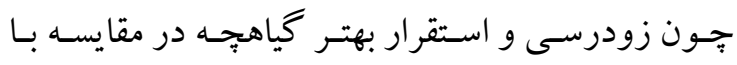

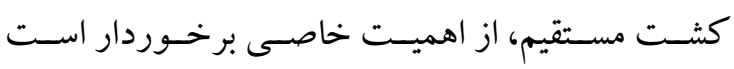
(Rahnema and Bakhshande, 2005) آبيارى و كاهش آب مصرفى (Dehghani et al., 2015)

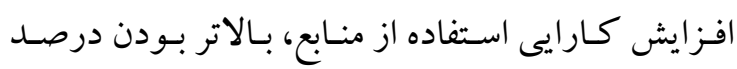

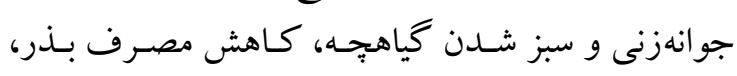

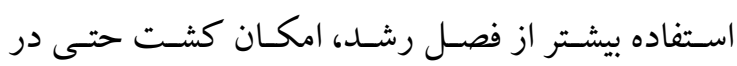

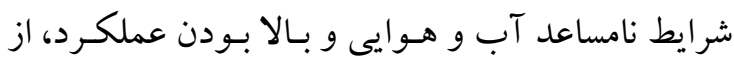

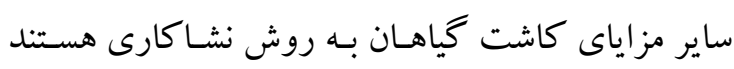

.(Fanadzo et al., 2009)

انتخاب شيوه مناسب خاككورزى براى زراعت كلزا

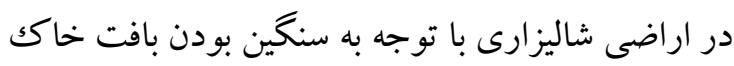

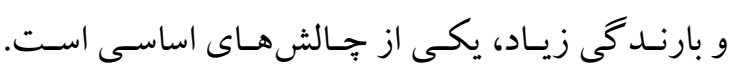

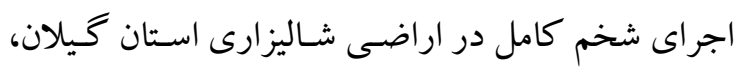

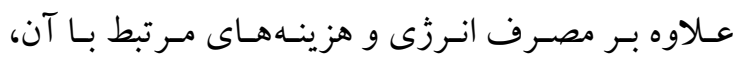

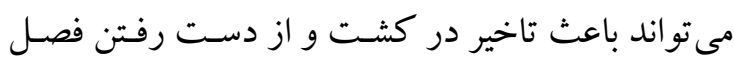

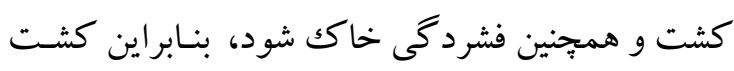

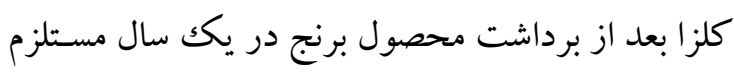

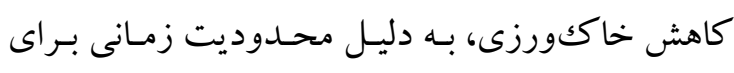

$$
\text { تهيه بستر محصول دوم مىباشد. }
$$

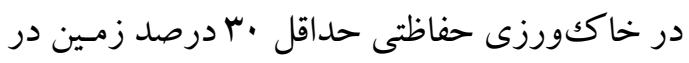

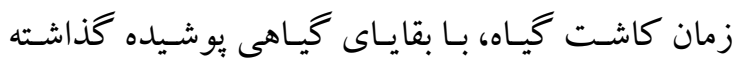

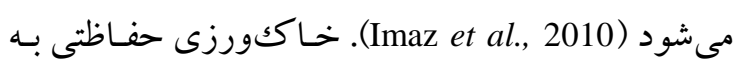
دليل حفظ بقاياى گياهى در سطح خاكك، جه در حالـ 
از برداشـت محصـول بـرنج عمليـات آمادهســى زمسين

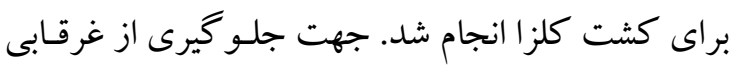
شدن مزرعه در اثر بارندگىهاى احتمالى، بين بلو ككهـا

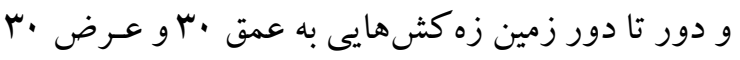

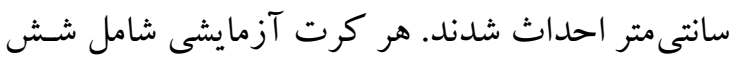

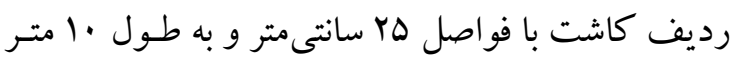
بود. فو اصل بين كرتها يكك متر و بين تكرارها سه متر در نظر گرفته شد. بر اساس نتايج آزمـون خـاكك (جـدول () و توصيه

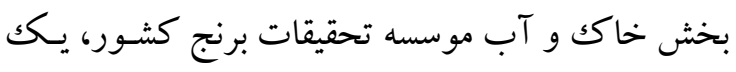

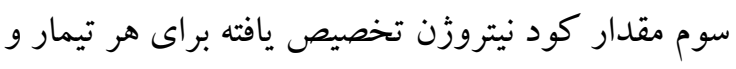

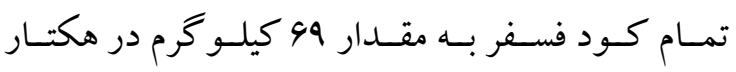

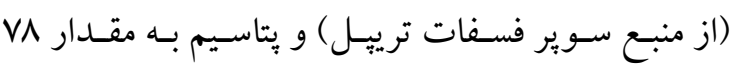

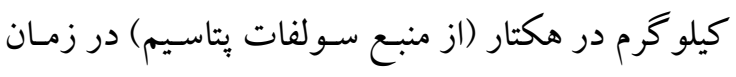

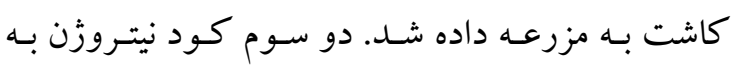

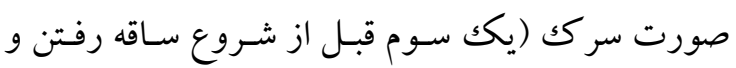
يكك سوم قبل از كلدهى) بر حسب تيمارهاى آزمايشى،

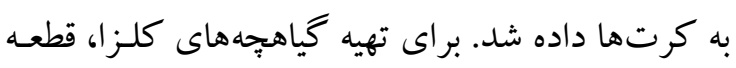

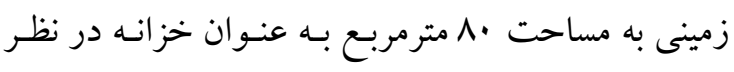

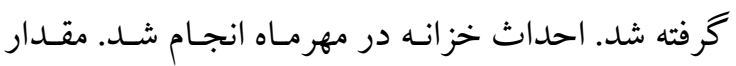

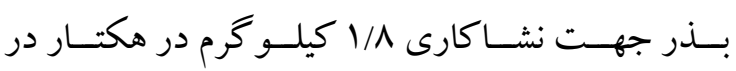
نظر گرفته شده و نشاكارى گياهجههاى كلزا به صورت

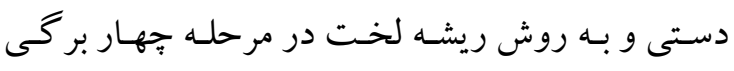

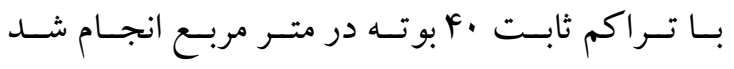

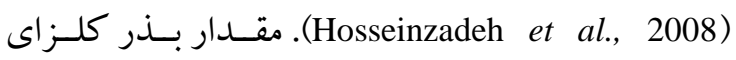
مورد استفاده بـراى كشـت مسـتقيم شـش كيلو گرم در هكتار در نظر كرفته شده و كاشـت بـــر در اوايـل آبـان

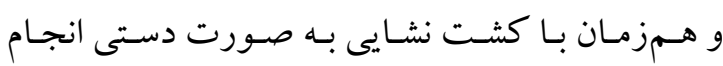

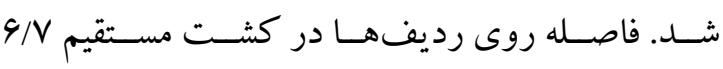

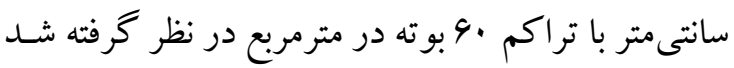
(Seed and Plant Improvement Institute, 2016) اندازهگيرى تعداد شاخه فرعى در بوته، تعداد خـورجين

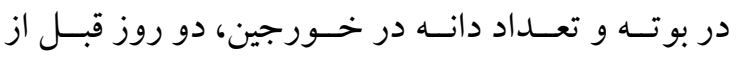

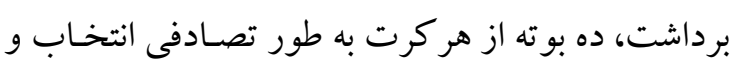

.2011; Mousavian et al., 2013) بر اساس اطلاعات نگًارند كان، تاكنون آزمايشى در

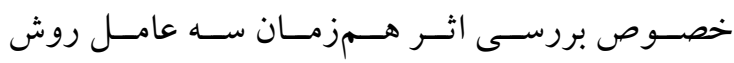

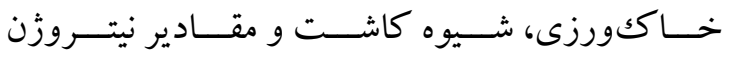

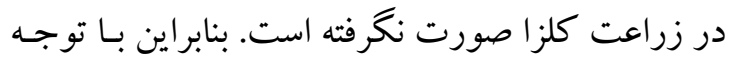

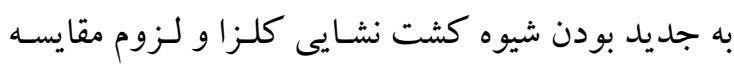

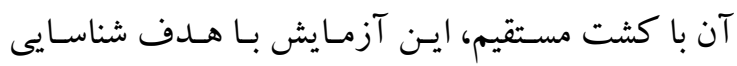

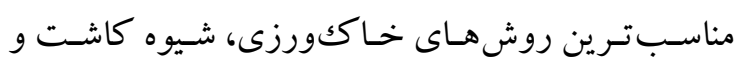

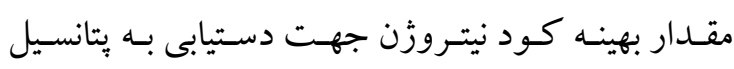

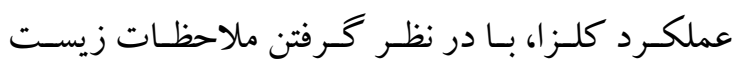

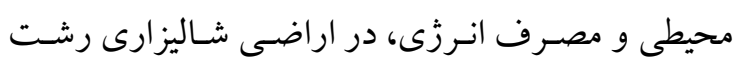
طراحى و اجرا شد.

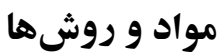

ايـن آزمـايش بـه صـورت اســليت فاكتوريـل در قالـب طـرح بلو ككهـاى كامـل تصـادفى بـا سـه تكـرار

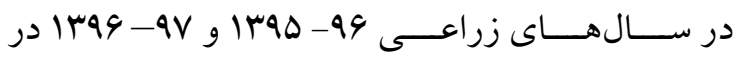

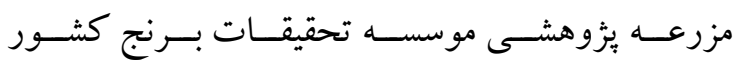

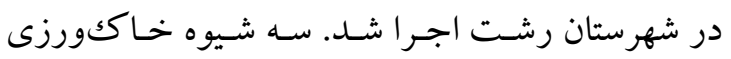

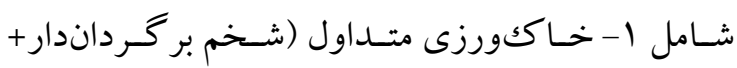
دوبار ديسك)، r r- كم خاكوروزى (يكك بار استفاده از

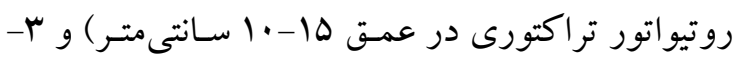
بدون خاككورزى (كاشت در شـيارهاى ايجـاد شـده بـا

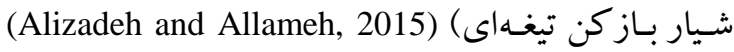
به عنوان كرتهاى اصلى و دو شيوه كاشت ا- مستقيم:

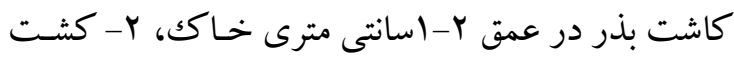

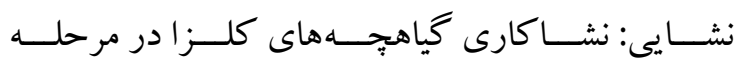

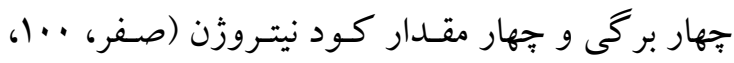

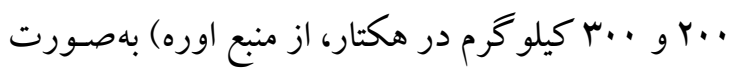
فاكتوريـل در كرتهـاى فرعسى در نظـر كرفتـه شـدند.

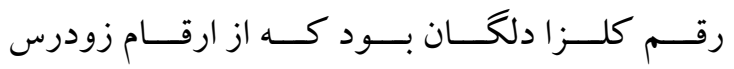

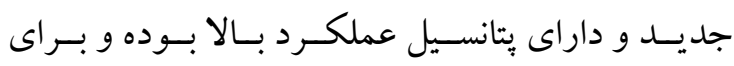

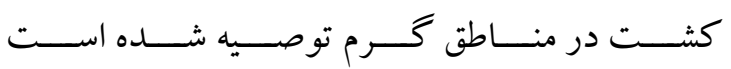
(Seed and Plant Improvement Institute, 2016) 
جدول ا- خصوصيات فيزيكى و شيميايى خاكك محل اجراى آزمايش

Table 1. Physicochemical properties of the soil at experiment site

\begin{tabular}{|c|c|c|c|c|c|c|c|c|c|}
\hline $\begin{array}{c}\text { بافت } \\
\text { Texture }\end{array}$ & $\begin{array}{c}\text { رس (\%) } \\
\text { Clay }\end{array}$ & $\begin{array}{c}\text { سيلت } \\
\text { Slit (\%) }\end{array}$ & $\begin{array}{c}\text { ش } \\
\text { Sand (\%) }\end{array}$ & $\begin{array}{l}\text { نيتروزن } \\
\text { N (\%) }\end{array}$ & $\begin{array}{c}\text { فسفر } \\
\mathrm{P}\left(\mathrm{mg} \mathrm{kg}^{-1}\right)\end{array}$ & $\begin{array}{c}\mathrm{rar} \\
\mathrm{K}\left(\mathrm{mg} \mathrm{kg}^{-1}\right) \\
\end{array}$ & $\begin{array}{l}\text { هدايت الكتريكى (dS.m.1- } \\
\text { EC }\end{array}$ & $\begin{array}{l}\text { اسيديته } \\
\text { pH }\end{array}$ & $\begin{array}{l}\text { كربن آلى } \\
\text { O.C (\%) }\end{array}$ \\
\hline Silty clay & 48 & 46 & 6 & 0.146 & 19.6 & 155 & 0.97 & 7.41 & 1.36 \\
\hline
\end{tabular}

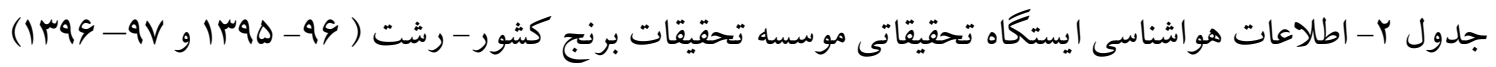

Table 2. Meteorological information of research station of Rice Research Institute of Iran, Rasht (2016-2018)

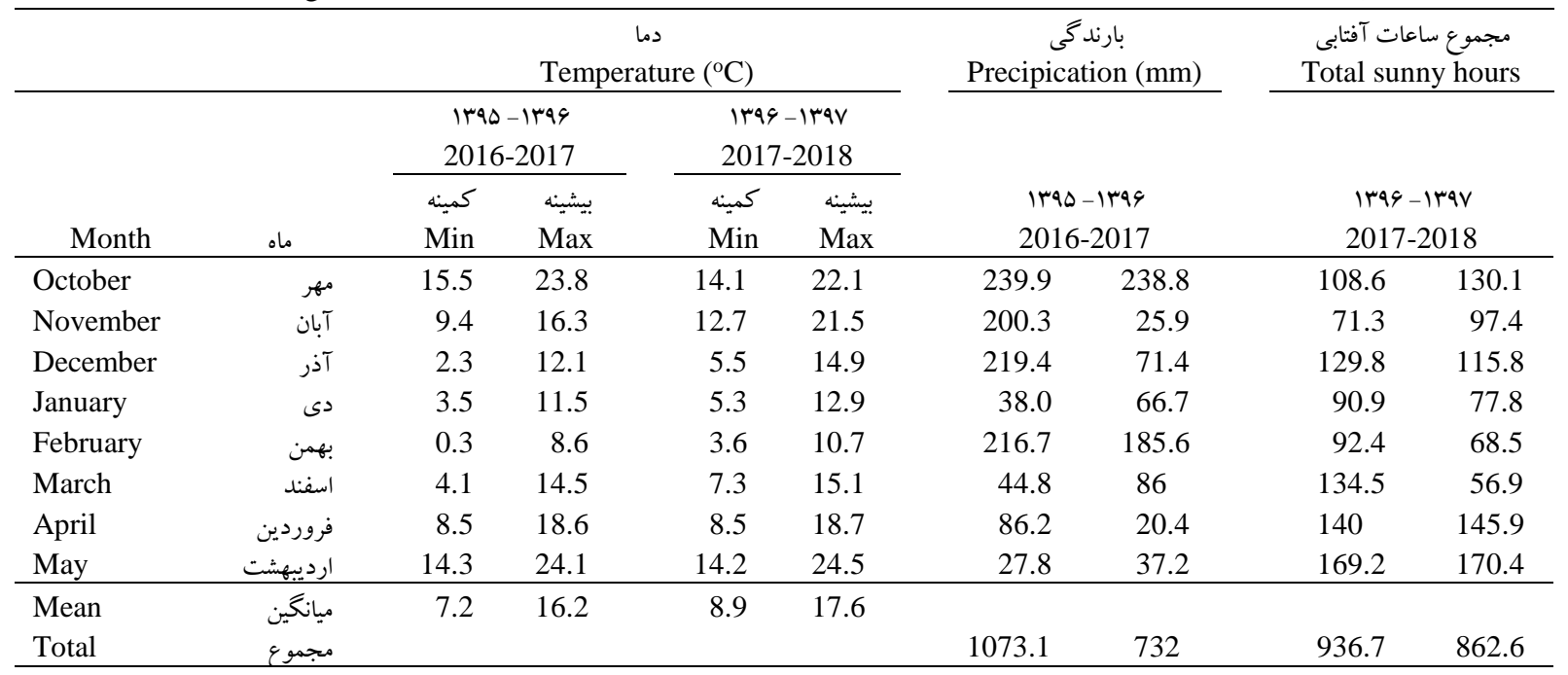


"اثر روش خاككورزى، شيوه كاشت...، ربيعى و همكاران،

و رسيدگى ديرتر بو تـهــا شـــ. نتـايج مقايسه ميـانغين

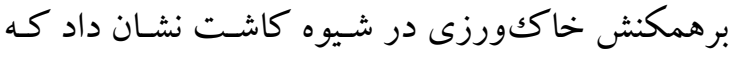
تر كيب تيمارى بدون خاككورزى در كشـت مستقيم بـا

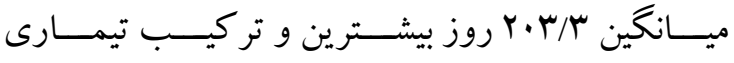

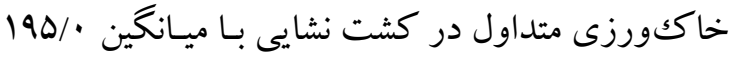

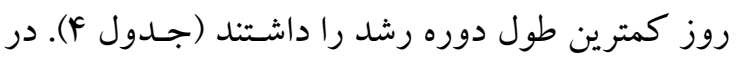

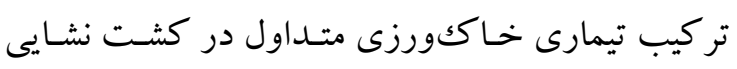

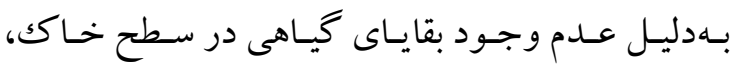

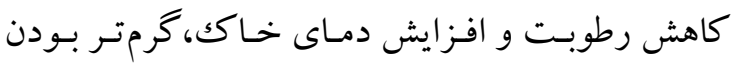

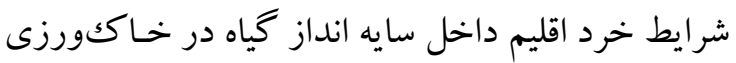

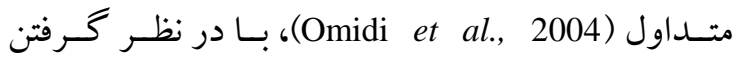
همزمانى كشت مستقيم و نشاكارى كياهجـهـهـاى كلـزا

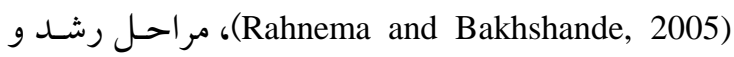
نمو گياه به سرعت سـبرى شـده و محصسول زودرستر

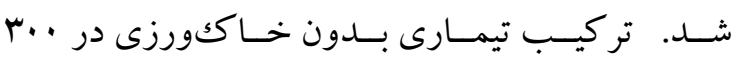

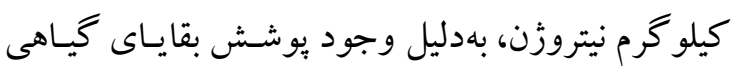

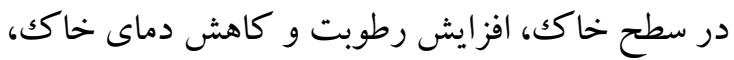
خنكك تر بودن خرد اقليم داخل سايه انـداز گيـاه، تـأخير

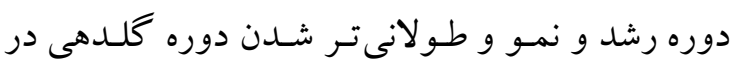
روش بدون خـاككورزى (Gajri et al., 2002)، افززايش

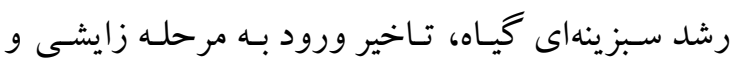
افزايش طـول دوره رشــد در اثر مصـرف مقــار بيشـتر نيتـروزن (Rameeh and Salimi, 2015)، بيشـترين طـول مول مهرد دوره رشد راد دارا بود (جدول ه).

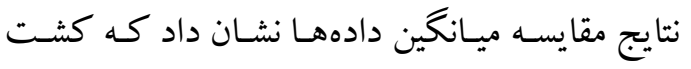

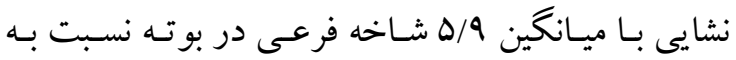

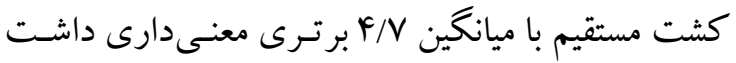

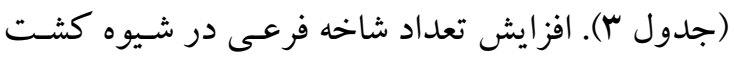

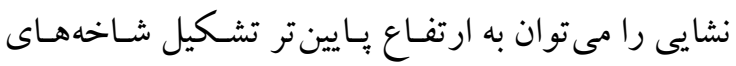

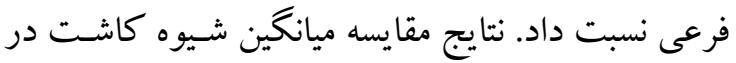

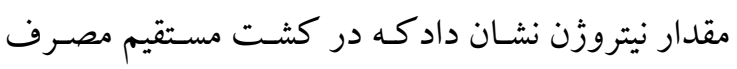

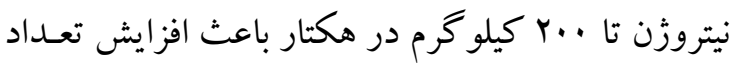

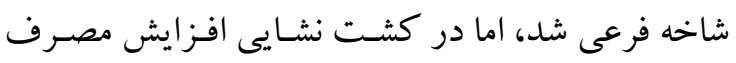

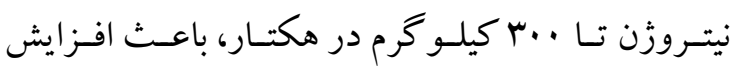

اندازه گيرىها انجـام و ميـانخين آنهـا ثبـت شـد. بـراى

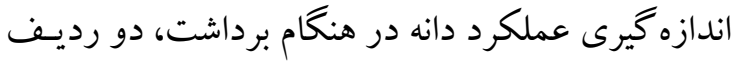

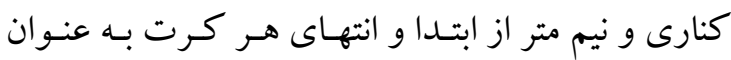
حاشيه حذف و بقيه به عنوان سطح برداشت انتخاب شد.

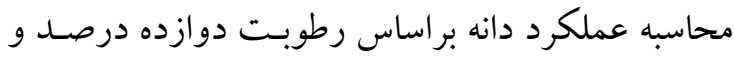

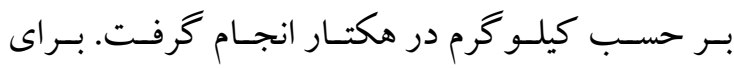

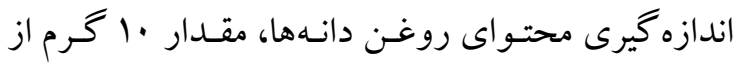

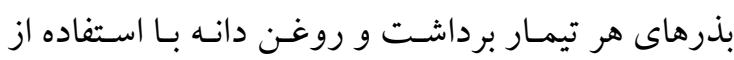

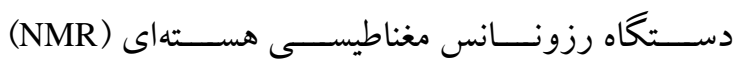

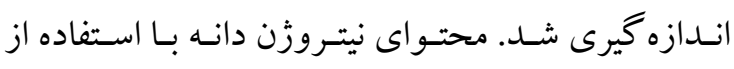

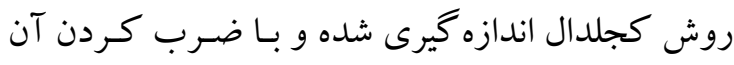

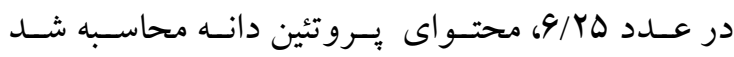
.(Rathke et al., 2005)

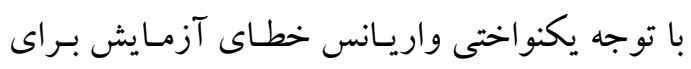

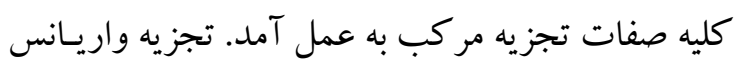

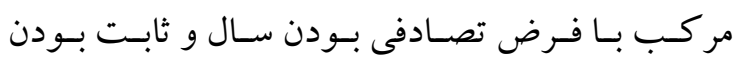

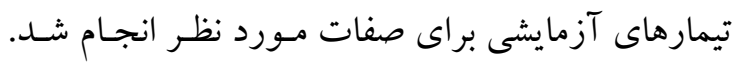

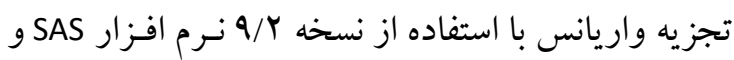

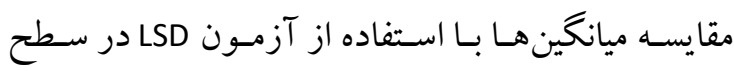
احتمال ينج درصد انجام شد.

\section{نتايج و بحث}

نتايج جدول تجزيه واريـانس مركب نشـان داد كـه

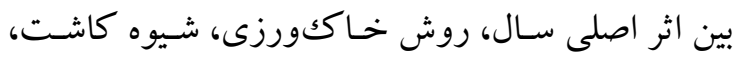

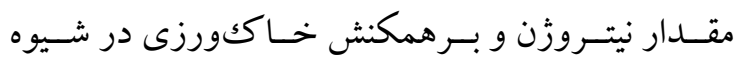
كاشت و خـاككورزى در مقـدار نيتـروزن از نظر طـول

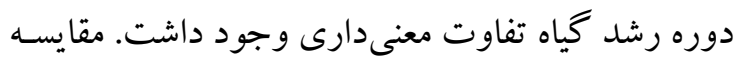

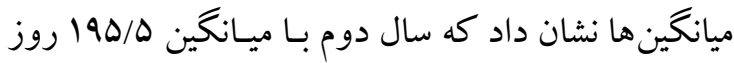

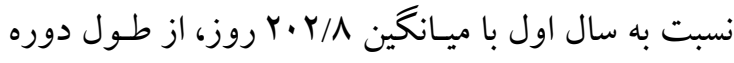

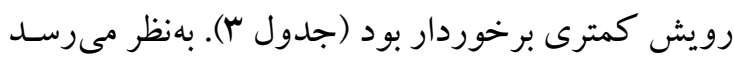

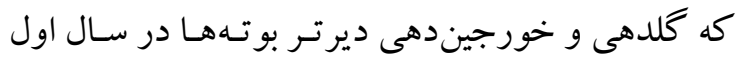

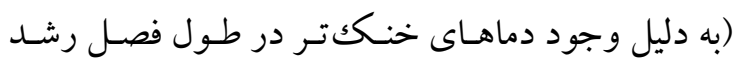

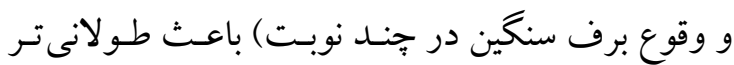

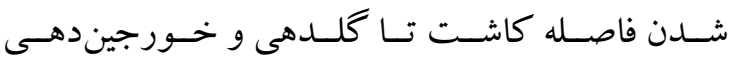


(Elewa et al., 2014; خورجين در بوته در تركيـب تيمارى كشـت نشـايى در

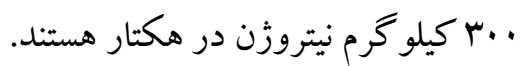

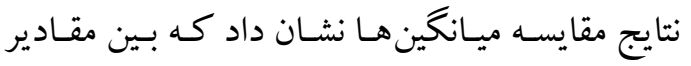

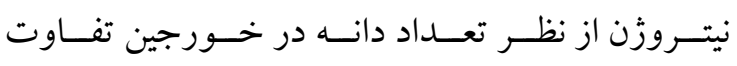

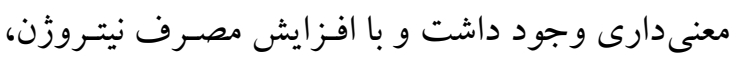

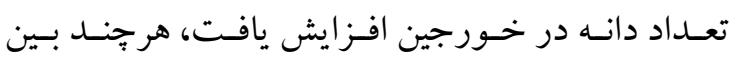

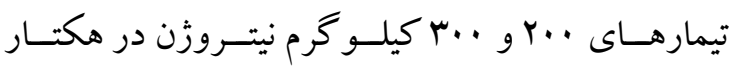

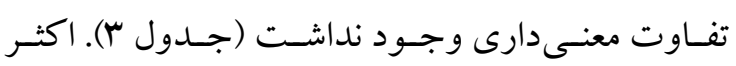

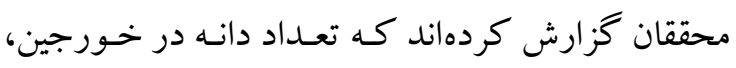
بيشتر تحت كنترل عوامل زنتيكى بوده و شر ايط محيطى

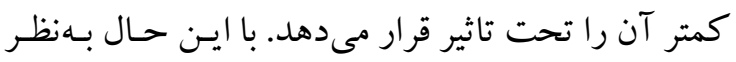

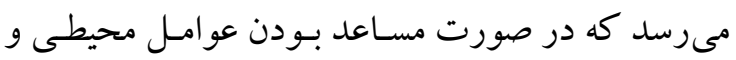

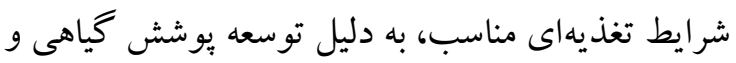

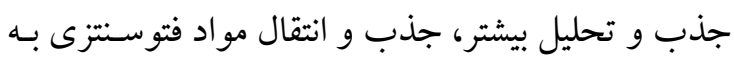
اندامهاى زايشى گياه مانند خورجين ها و تعسداد دانسه در خورجين افزايش يافته و عملكرد بيشترى توليد مىشود (Ozturk, 2010; Tahmasebi et al., 2013; Rameeh and

.Salimi, 2015)

نتايج مقايسه ميانخين دادهها نشان داد كـه تيمارهـاى

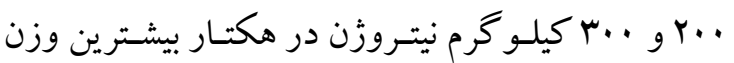

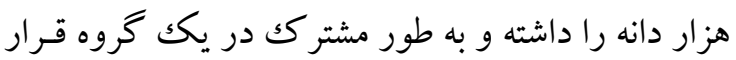

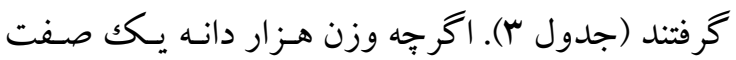

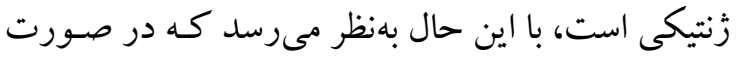

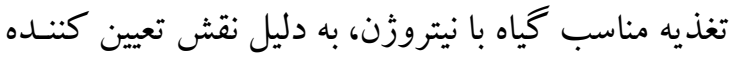
نيتروزن در توسـعه يوشـش گيـاهى و سطح سـبز گيـاه،

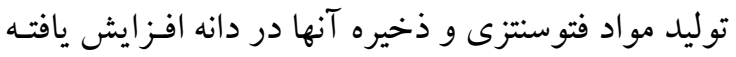

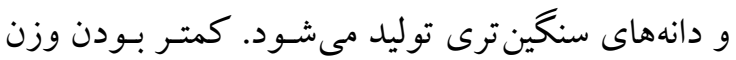

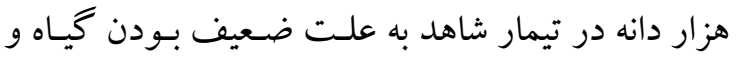

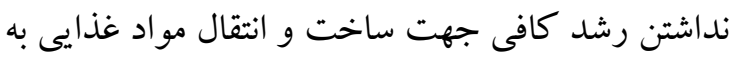

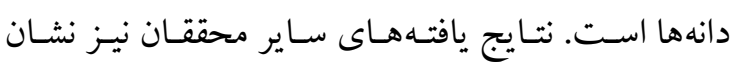

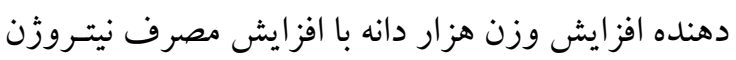

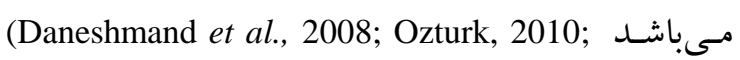
.Kazemeini et al., 2010) شاخههاى فرعى شد (جدول 9). نتايج آزمايش وانگك و

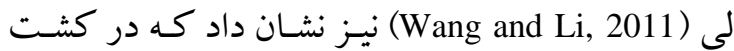

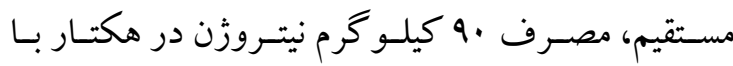

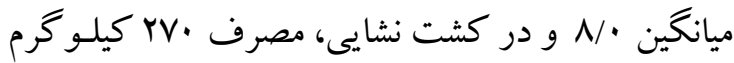

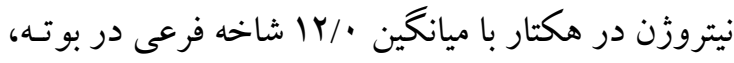

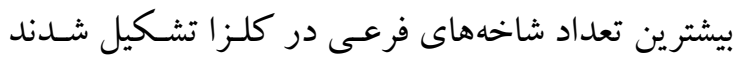

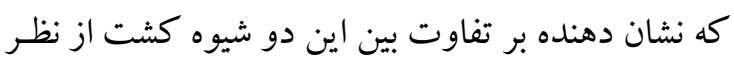

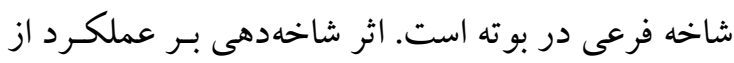

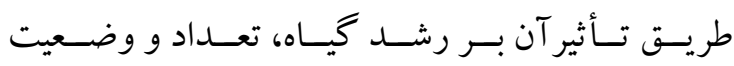

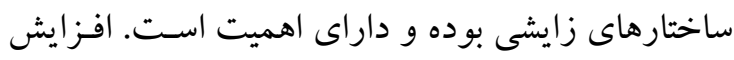
مصرف نيتروزن به دليل افزايش سطح سبز فتوسنتز كننده

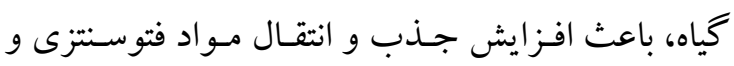

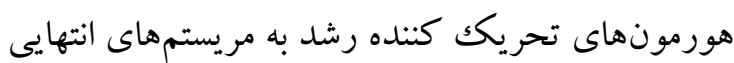

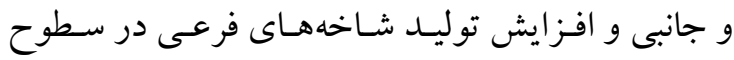
بالاتر نيتروزن مىشود (Mirzapour et al., 2014).

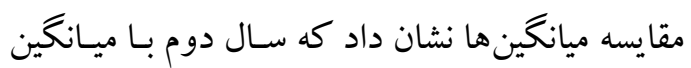
19V/9 خورجين در بوته نسبت بـه سـال اول بـا ميـانكين

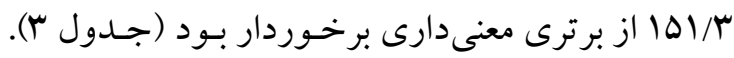
دليـل اصـلى افـزايش تعـــاد خــورجين در ســال دوم

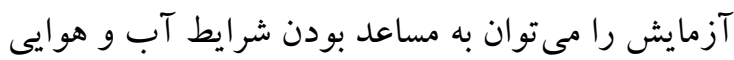
و افزايش زيست توده و تعداد شاخههاى فرعى در بوتـه

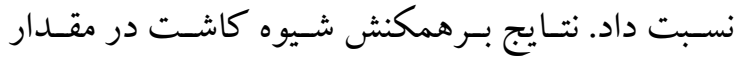
نيتروزن نشان داد كـه تركيـب تيمـارى كشـت نشـايى و

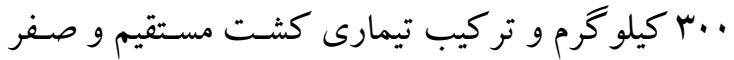
كيلو گرم نيتروزن در هكتار (بهترتيب با ميانگين و V9/T خورجين در بوته) رتبههاى اول و آخر را داشته و در گروههاى مجزاى آمارى قرار گرفتند (جدول 9).

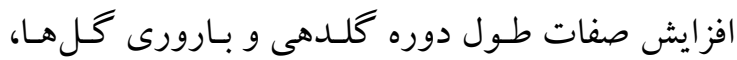

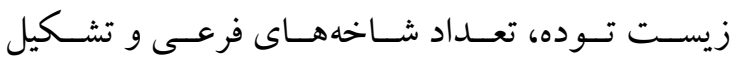

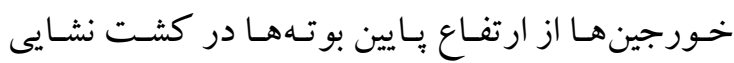
Rahnema and Bakhshand, 2005; Wang and Li, (2011) و بارورى گل هـا و تعـداد شـاخههاى فرعى در

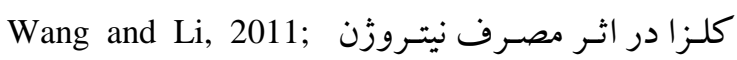
Mirzapour et al., 201; Rameeh and Salimi, 2015) 


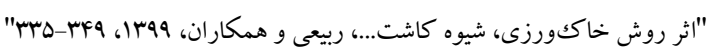

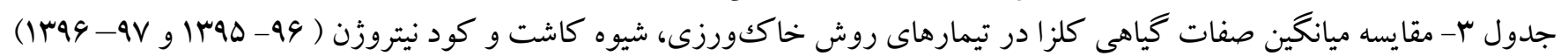

Table 3. Mean comparison of plant traits of rapeseed in tillage system, planting method and nitrogen fertilizer rate treatments (2016-2018)

\begin{tabular}{|c|c|c|c|c|c|c|c|}
\hline Treatments & تيمارهاى آزمايشى & $\begin{array}{c}\text { طول دوره رشد } \\
\text { Days to maturity }\end{array}$ & 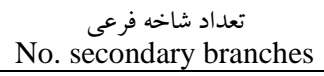 & $\begin{array}{l}\text { خورجين در بو ته } \\
\text { Silique.plant } \\
\end{array}$ & $\begin{array}{l}\text { دانه در خورجين } \\
\text { Seed.silique } \\
\end{array}$ & $\begin{array}{c}\text { وزن هزاردانه } 1000 \text { seed weight (g) } \\
100 \text {. }\end{array}$ & $\begin{array}{c}\text { عملكرد دانه } \\
\left.\text { Seed yield (kg.ha }{ }^{-1}\right)\end{array}$ \\
\hline Year & سال & & & & & & \\
\hline 2016-2017 & $1 \% q \Delta-1 r q 9$ & $202.8 \mathrm{a}$ & $5.2 \mathrm{~b}$ & $151.3 \mathrm{~b}$ & $21.1 \mathrm{~b}$ & $3.99 \mathrm{a}$ & $3054 b$ \\
\hline $2017-2018$ & |raq-1rqV & $195.5 b$ & $5.4 \mathrm{a}$ & $167.9 \mathrm{a}$ & $22.1 \mathrm{a}$ & $4.04 \mathrm{a}$ & $3349 a$ \\
\hline Tillage system & روش خاككورزى & & & & & & \\
\hline No tillage & بدون خاككورزى & $201.7 \mathrm{a}$ & $5.1 \mathrm{a}$ & $150.6 b$ & $21.7 \mathrm{a}$ & $4.04 \mathrm{a}$ & $2944 b$ \\
\hline Minimum tillage & كم خاكورزى & $198.6 b$ & $5.3 \mathrm{a}$ & $162.8 \mathrm{a}$ & $21.4 \mathrm{a}$ & $4.02 \mathrm{a}$ & $3303 a$ \\
\hline Conventional tillage & خاككورزى متداول & $197.8 \mathrm{~b}$ & $5.5 \mathrm{a}$ & $165.5 \mathrm{a}$ & $21.7 \mathrm{a}$ & $3.99 \mathrm{a}$ & $3357 \mathrm{a}$ \\
\hline Planting method & شيوه كاشت & & & & & & \\
\hline Direct seeding & بذر كارى مستقيم & $201.7 \mathrm{a}$ & $4.7 \mathrm{~b}$ & $125.3 \mathrm{~b}$ & $21.5 \mathrm{a}$ & $4.02 \mathrm{a}$ & $3156 b$ \\
\hline Transplanting & نشاكارى & $196.6 \mathrm{~b}$ & $5.9 \mathrm{a}$ & $193.9 \mathrm{a}$ & $21.7 \mathrm{a}$ & $4.01 \mathrm{a}$ & $3246 a$ \\
\hline Nitrogen fertilizer $\left(\mathrm{kg} \cdot \mathrm{ha}^{-1}\right)$ & كود نيتروزن & & & & & & \\
\hline 0 & صفر & $197.4 d$ & $3.8 \mathrm{~d}$ & $90.5 \mathrm{~d}$ & $20.1 \mathrm{c}$ & $3.74 \mathrm{c}$ & $1472 \mathrm{c}$ \\
\hline 100 & $1 .$. & $198.8 \mathrm{c}$ & $5.1 \mathrm{c}$ & $157.8 \mathrm{c}$ & $21.3 \mathrm{~b}$ & $4.01 \mathrm{~b}$ & $3240 \mathrm{~b}$ \\
\hline 200 & r.. & $199.9 b$ & $6.0 \mathrm{~b}$ & $188.7 \mathrm{~b}$ & $22.4 \mathrm{a}$ & $4.15 \mathrm{a}$ & $4001 \mathrm{a}$ \\
\hline 300 & $r .$. & $200.5 \mathrm{a}$ & $6.2 \mathrm{a}$ & $201.5 \mathrm{a}$ & $22.5 \mathrm{a}$ & $4.16 \mathrm{a}$ & $4092 \mathrm{a}$ \\
\hline
\end{tabular}

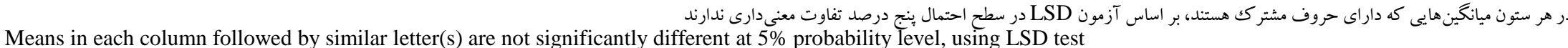

Table 3. Continued

جدول r- ادامه

\begin{tabular}{|c|c|c|c|c|c|c|c|}
\hline Treatments & تيمارهاى آزمايشى & 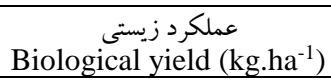 & $\begin{array}{c}\text { شاخص برداشت } \\
\text { Harvest index (\%) }\end{array}$ & $\begin{array}{c}\text { روغن دانه }(\%) \\
\text { Oil content (\%) }\end{array}$ & $\begin{array}{c}\text { عملكرد روغن } \\
\text { Oil yield }\left({\left.\mathrm{kg} \cdot h \mathrm{ha}^{-1}\right)}^{-}\right.\end{array}$ & $\begin{array}{c}\text { يروتئين دانه } \\
\text { Protein content (\%) }\end{array}$ & $\begin{array}{c}\text { عملكرد بروتئين } \\
\text { Protein yield }\left(\mathrm{kg}^{2} \mathrm{ha}^{-1}\right)\end{array}$ \\
\hline Year & سال & & & & & & \\
\hline $2016-2017$ & $1 \% q \Delta-1 \% a q$ & $9399 b$ & $31.6 \mathrm{~b}$ & $43.1 \mathrm{a}$ & $1306 \mathrm{~b}$ & $18.7 b$ & $584.1 \mathrm{~b}$ \\
\hline $2017-2018$ & |rag-Irav & $9805 a$ & $33.2 \mathrm{a}$ & $42.2 \mathrm{~b}$ & $1403 \mathrm{a}$ & $20.7 \mathrm{a}$ & $714.5 \mathrm{a}$ \\
\hline Tillage system & روش خاككورزى & & & & & & \\
\hline No tillage & بدون خاكورزى & $8929 b$ & $32.0 \mathrm{a}$ & $42.6 \mathrm{a}$ & $1243 b$ & $19.8 \mathrm{a}$ & $604.0 \mathrm{~b}$ \\
\hline Minimum tillage & كم خاكورزى & $9867 \mathrm{a}$ & $32.6 \mathrm{a}$ & $42.5 \mathrm{a}$ & $1394 a$ & $19.8 \mathrm{a}$ & $672.7 \mathrm{a}$ \\
\hline Conventional tillage & خاككورزى متداول & $10010 \mathrm{a}$ & $32.6 \mathrm{a}$ & $42.8 \mathrm{a}$ & $1426 \mathrm{a}$ & $19.5 \mathrm{a}$ & $671.1 \mathrm{a}$ \\
\hline Planting method & شيوه كاشت & & & & & & \\
\hline Transplanting & نشاكارى & $9727 \mathrm{a}$ & $32.4 \mathrm{a}$ & $42.8 \mathrm{a}$ & $1379 \mathrm{a}$ & $19.8 \mathrm{a}$ & $663.8 \mathrm{a}$ \\
\hline Nitrogen fertilizer $\left(\mathrm{kg} \cdot \mathrm{ha}^{-1}\right)$ & كود نيتروزن & & & & & & \\
\hline 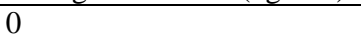 & صفر & $5854 d$ & $25.2 b$ & $44.2 \mathrm{a}$ & $652 \mathrm{c}$ & $17.3 \mathrm{~d}$ & $256.4 \mathrm{~d}$ \\
\hline 100 & 1... & $9311 \mathrm{c}$ & $34.8 \mathrm{a}$ & $43.1 b$ & $1396 b$ & $19.0 \mathrm{c}$ & $618.4 \mathrm{c}$ \\
\hline 200 & r.. & $11345 b$ & $35.3 \mathrm{a}$ & $42.0 \mathrm{c}$ & $1681 \mathrm{a}$ & $20.7 b$ & $830.6 \mathrm{~b}$ \\
\hline 300 & $\mu .$. & $11898 \mathrm{a}$ & $34.4 \mathrm{a}$ & $41.2 \mathrm{~d}$ & $1690 \mathrm{a}$ & $21.7 \mathrm{a}$ & $891.71 \mathrm{a}$ \\
\hline
\end{tabular}

Means in each column followed by similar letter(s) are not significantly different at 5\% probability level, using LSD test 


$$
\text { "نشريه علوم زراعى ايران"، جلد بيست و دوم، شماره و، زمستان }
$$

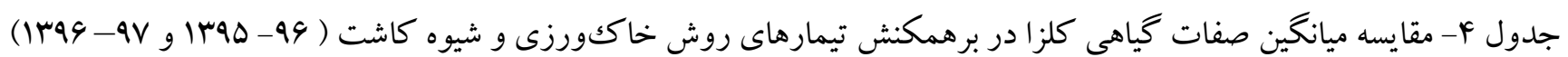

Table 4. Mean comparison of plant traits of rapeseed in interaction effect of tillage system and planting method treatments (2016-2018)

\begin{tabular}{|c|c|c|c|c|c|c|}
\hline Tillage system & روش خاككورزى & Planting method & شيوه كاشت & $\begin{array}{c}\text { طول دوره رشد } \\
\text { Days to maturity }\end{array}$ & $\begin{array}{c}\text { تعداد شاخه فرعى } \\
\text { No. secondary branches }\end{array}$ & $\begin{array}{c}\text { عملكرد دانه } \\
\text { Seed yield }\left(\mathrm{kg} \mathrm{kga}^{-1}\right) \\
\end{array}$ \\
\hline \multirow{2}{*}{ No tillage } & \multirow{2}{*}{ بدون خاككورزى } & Direct seeding & بذر كارى مستقيم & $203.3 \mathrm{a}$ & $4.4 \mathrm{~d}$ & $2967 d$ \\
\hline & & Transplanting & 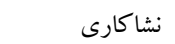 & $198.9 d$ & $5.8 \mathrm{a}$ & $2920 d$ \\
\hline \multirow{2}{*}{ Minimum tillage } & \multirow{2}{*}{ كم خاككورزى } & Direct seeding & بذر كارى مستقيم & $201.4 b$ & $4.7 \mathrm{c}$ & $3246 b c$ \\
\hline & & Transplanting & نشاكارى & $195.8 \mathrm{e}$ & $5.9 \mathrm{a}$ & $3360 \mathrm{ab}$ \\
\hline \multirow{2}{*}{ Conventional tillage } & \multirow{2}{*}{ خاككورزى متداول } & Direct seeding & بذر كارى مستقيم & $200.5 \mathrm{c}$ & $5.1 \mathrm{~b}$ & $3256 \mathrm{bc}$ \\
\hline & & Transplanting & نشاكارى & 195.0f & $5.9 \mathrm{a}$ & $3458 \mathrm{a}$ \\
\hline
\end{tabular}

Means in each column followed by similar letter(s) are not significantly different at 5\% probability level, using LSD test

جدول ه- مقايسه ميانگين صفات كياهى كلزا در برهمكنش تيمارهاى روش خاككورزى و مقدار نيتروزن ( 94- هوسا و 9V- 9

Table 5. Mean comparison of plant traits of rapeseed in interaction effect of tillage system and nitrogen fertilizer treatments (2016-2018)

\begin{tabular}{|c|c|c|c|c|c|c|}
\hline Tillage system & روش خاككورزى & Nitrogen fertilizer $\left(\mathrm{kg} \cdot \mathrm{ha}^{-1}\right)$ & كود نيتروزن & $\begin{array}{c}\text { طول دوره رشد } \\
\text { Days to maturity }\end{array}$ & $\begin{array}{c}\text { عملكرد دانه } \\
\text { Seed yield }\left(\mathrm{kg}^{2} \mathrm{ha}^{-1}\right) \\
\end{array}$ & $\begin{array}{c}\text { عملكرد روغن } \\
\text { Oil yield (kg.ha-1) }\end{array}$ \\
\hline \multirow[t]{4}{*}{ No tillage } & \multirow[t]{4}{*}{ بدون خاككورزى } & 0 & صفر & $199.1 \mathrm{e}$ & $1325 \mathrm{~g}$ & $589 \mathrm{f}$ \\
\hline & & 100 & $1 .$. & $200.6 \mathrm{c}$ & $2840 \mathrm{e}$ & $1223 d$ \\
\hline & & 200 & r.. & $201.9 \mathrm{~b}$ & $3667 \mathrm{c}$ & $1531 \mathrm{c}$ \\
\hline & & 300 & r.. & $202.8 \mathrm{a}$ & $3942 b$ & $1627 b$ \\
\hline \multirow[t]{4}{*}{ Minimum tillage } & \multirow[t]{4}{*}{ كم خاككورزى } & 0 & صفر & $197.0 \mathrm{~g}$ & $1540 \mathrm{f}$ & $681 \mathrm{e}$ \\
\hline & & 100 & $1 .$. & $198.3 f$ & $3379 d$ & $1449 \mathrm{c}$ \\
\hline & & 200 & $r \cdot$. & $199.0 \mathrm{e}$ & $4144 a$ & $1737 \mathrm{a}$ \\
\hline & & 300 & r.. & $200.0 \mathrm{~d}$ & $4149 a$ & $1710 \mathrm{ab}$ \\
\hline \multirow[t]{4}{*}{ Conventional tillage } & \multirow[t]{4}{*}{ خاككورزى متداول } & 0 & صفر & $196.2 \mathrm{~h}$ & $1551 f$ & $686 \mathrm{e}$ \\
\hline & & 100 & $1 .$. & $197.4 \mathrm{~g}$ & $3501 \mathrm{~cd}$ & $1515 \mathrm{c}$ \\
\hline & & 200 & r.. & $198.7 \mathrm{ef}$ & $4191 \mathrm{a}$ & $1773 \mathrm{a}$ \\
\hline & & 300 & $r .$. & $198.8 \mathrm{e}$ & $4185 \mathrm{a}$ & $1730 \mathrm{a}$ \\
\hline
\end{tabular}

Means in each column followed by similar letter(s) are not significantly different at 5\% probability level, using LSD test 
"اثر روش خاككورزى، شيوه كاشت...، ربيعى و همكاران،

(جدول ه). بهنظر مىرسد كه تلفـات بيشـتر نيتـروزن در

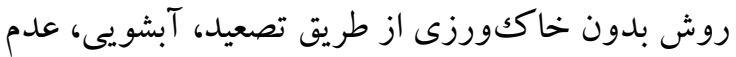

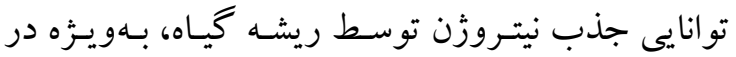

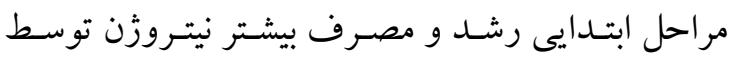

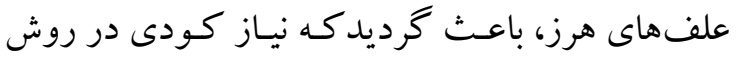

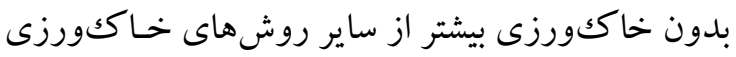

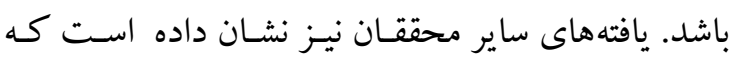

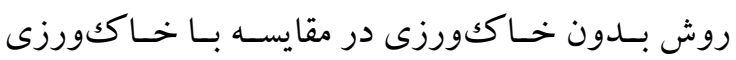

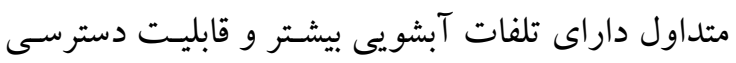

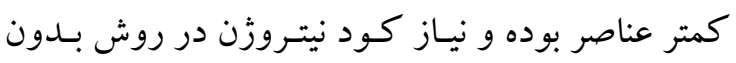

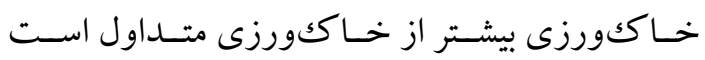
.(Hernan et al., 2000)

بررسى نتسايج بـرهمكنش روش كاشـت در مقـدار

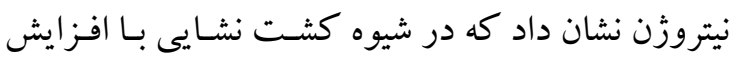

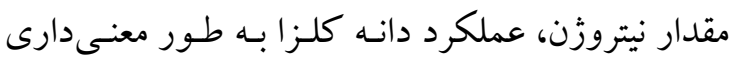

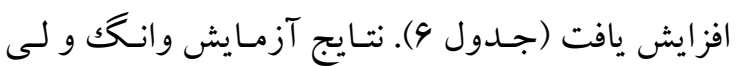
(Wang and Li, 2011)

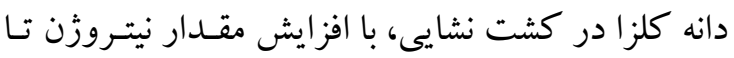

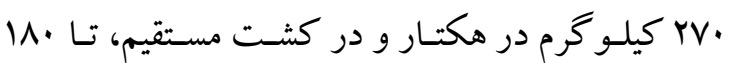

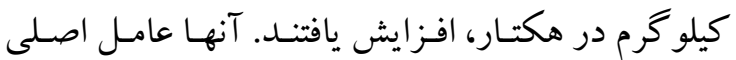
افزايش عملكرد دانه با مصرف مقدار بيشـتر نيتـروزن در روش كشت نشايى را به افزايش تعداد شاخههاى فرعى بـى و تعداد خورجين در بوته مربـوط دانستـند كـه بـا نتـايج آزمايش حاضر مطابقت دارد. نتايج مقايسه ميانگين ها نشان داد كه از نظر شـاخص دارد

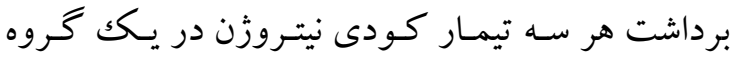

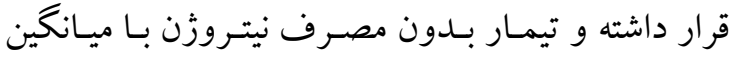

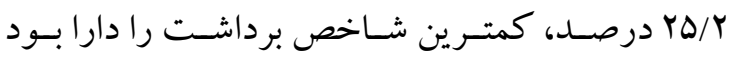

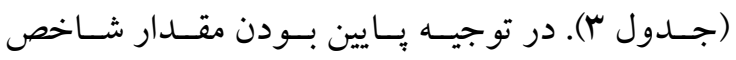

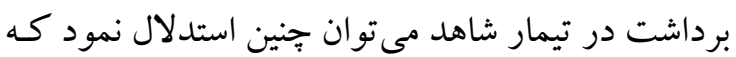
در شر ايط كمبود نيتروزن افز ايش عملكرد زيستى بيشتر

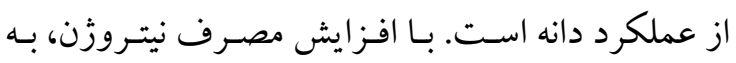
دليـل بهــوهورى بيشـتر كيـاه كلـزا از نيتـروزن، افـزايش

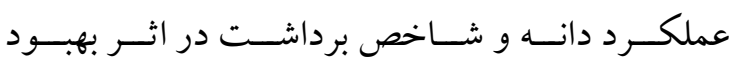

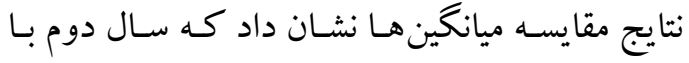

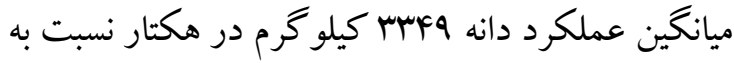

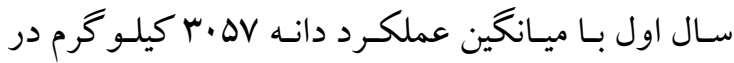

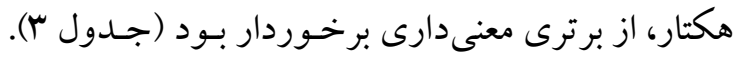

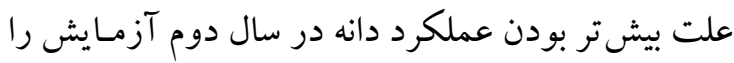

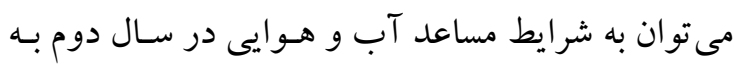

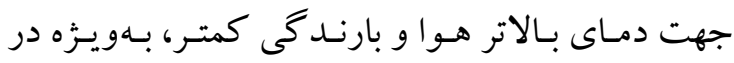

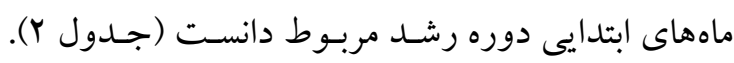

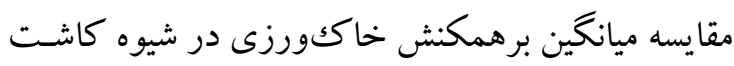
نشان داد كه خاككورزى متداول در شيوه كشت نشايى مئ برهي

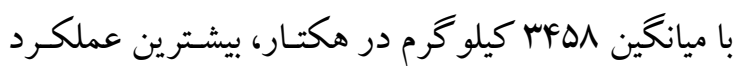

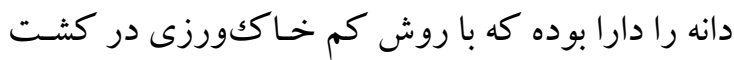

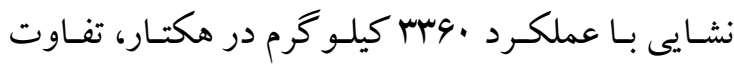
معنى دارى نداشت (جدول f). با توجه به اينكه عمليـات خاككورزى با ايجاد تغيير در ساختمان خـاكى، شكستـن

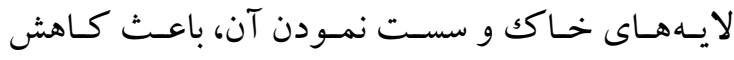

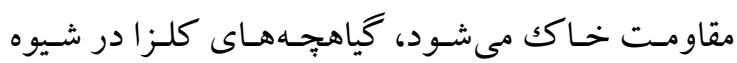
كشت نشايى بهدليل بهبـود شـر ايط فيزيكى و شـيميايى

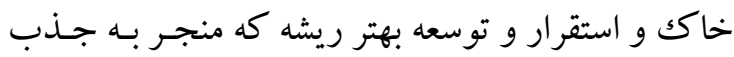

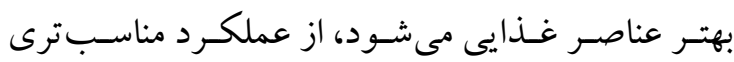

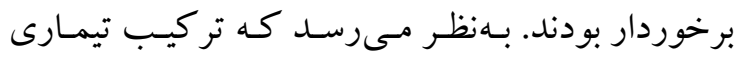
بــدون خـاككورزى در هـر دو شـيوه كاشـت، بـهدليـل

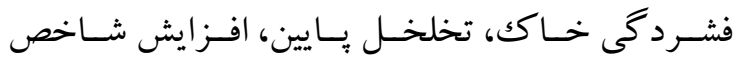

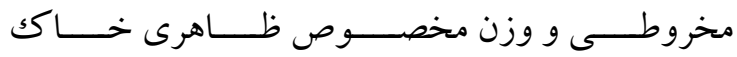
باعثث (Mohammadi et al., 2009, Gajri et al., 2002) مقاومت بيشتر خاكك به نفوذ ريشه كلـزا شـده و كاهش طول ريشه و كاهش عملكرد در ايـن تيمارهـا بـه وقوع

$$
\text { بيوست. }
$$

نتــايج بـــرهمكنش روش خــاككورزى در مقــدار نيتروزن نشان داد كه در تيمارهاى خـاككورزى متـداول

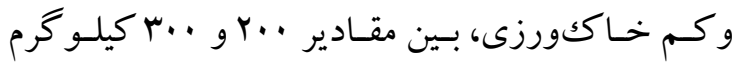

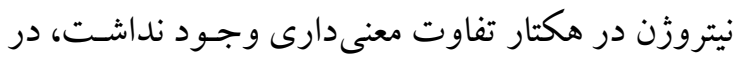

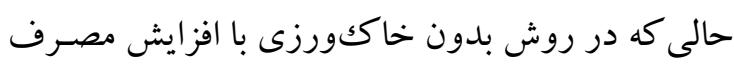

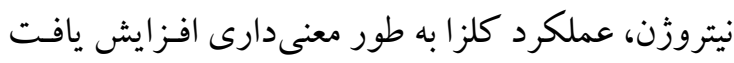


اختصـاص يافتسه و توليـــ هيـدراتهاى كـربن كـاهش مى يابد كه اين موضوع باعث كاهش ميزان روغـن دانـه

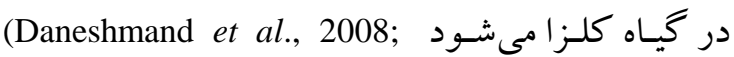

.Taheri et al., 2012; Mirzapour et al., 2014) نتسايج مقايسـه ميانخين هـا نشـان داد كـه سـال دوم

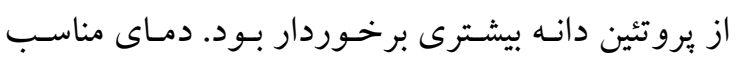

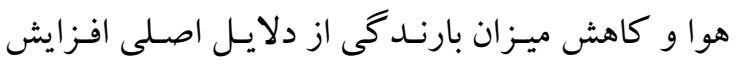

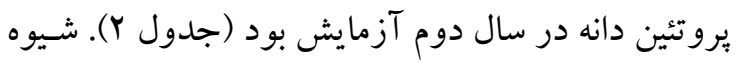

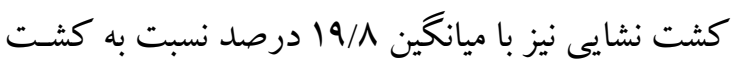

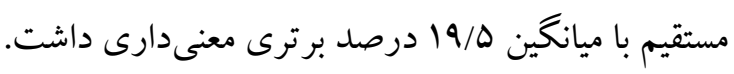

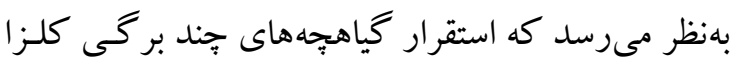

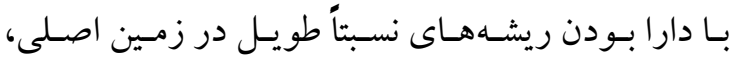
باعث جذب بيشتر نيتروزن و تلفات كمتر آن نسـبت بـهـ كشت مستقيم شــده و از ايـن رو محتـواى يـروتئين دانـه

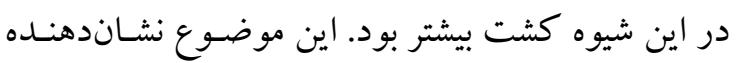

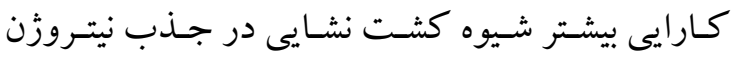
اسـت. بـا افـز ايش مصـرف نيتـروزن، درصــ يــروتئين

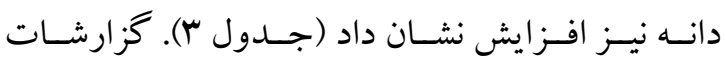

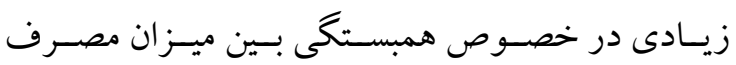

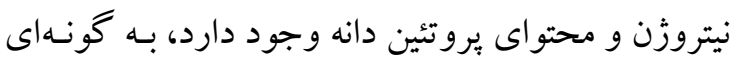
كه با افزايش مصـرف نيتـروزن، محتـواى يـروتئين دانـه

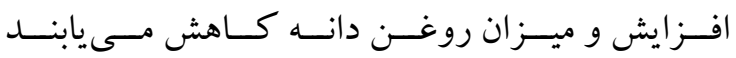

.(Daneshmand et al., 2008)

\section{نتيجه كيرى}

نتايج اين تحقيق نشان داد كـه تركيـب تيمـارى كـم دئم خاككورزى در شيوه كشت نشـايى داراى اثر مثبـت بـر عملكرد دانه و صفات مهم زراعى كلزا بوده و مى تو انسـ

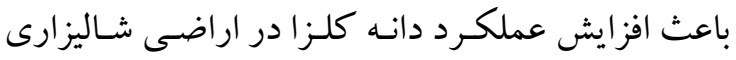
شود. با توجه به اين كه توسعه سطح زير كشـت كلـزا بـا فيا روش خـاككورزى متـداول و شـيوه كشـت مسـتقيم در

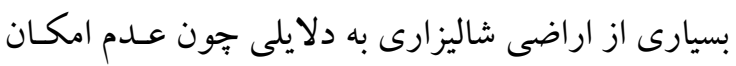

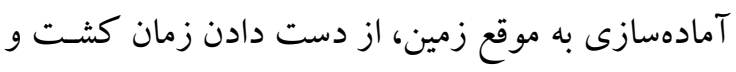

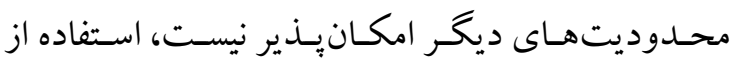

سـاختارهاى زايشـى، بـه نحـوى كـه مقــدار بيشـترى از

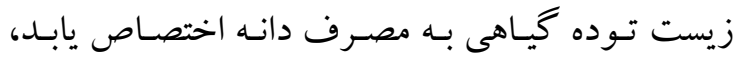

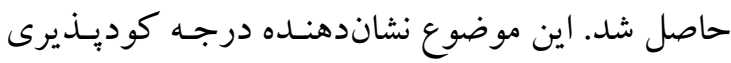

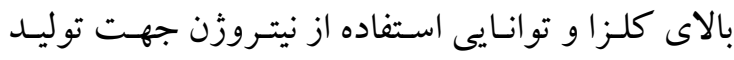

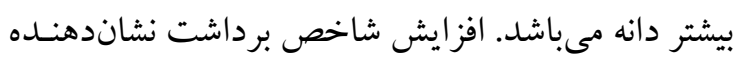

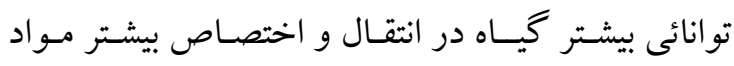

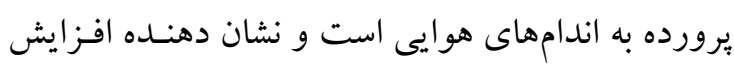

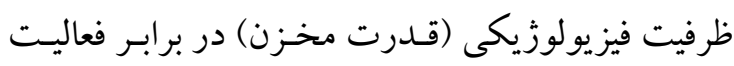

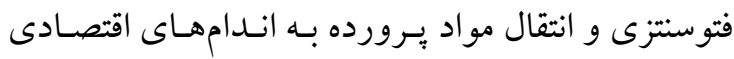

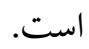

نتـايج مقايسـه ميانگين هـا نشـان داد كـه سـال اول بـا ميانگين /F/F

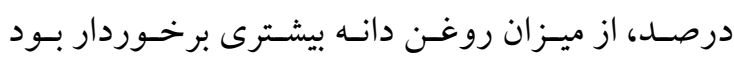

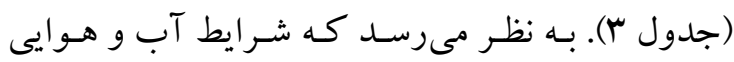

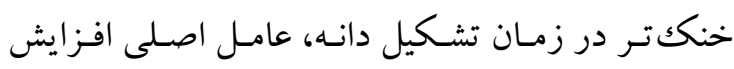

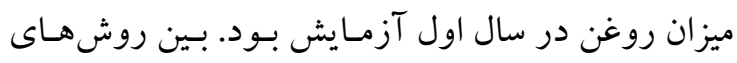

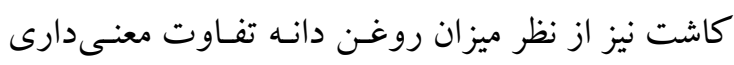
وجود داشت. كشت نشايى نسبت به كشـت مستقيم ، از

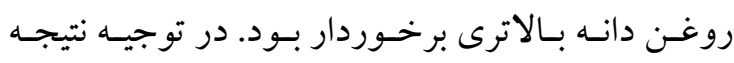

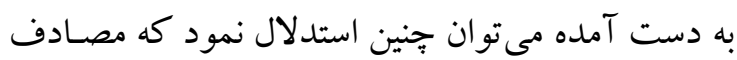

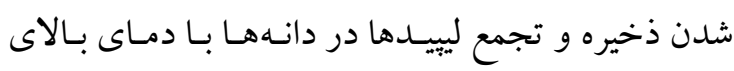

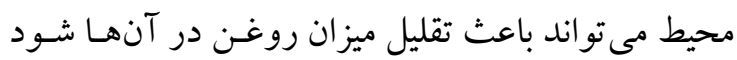

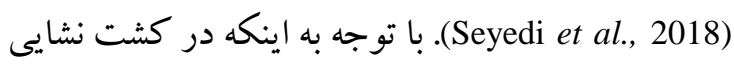

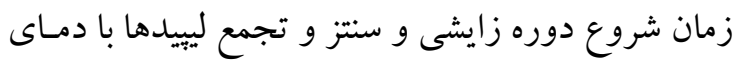

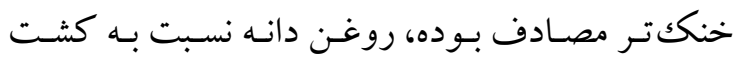

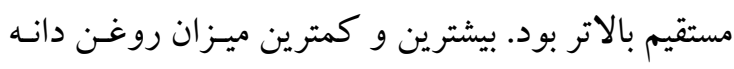

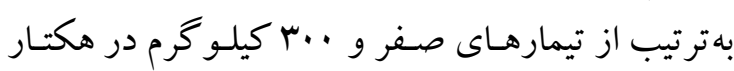

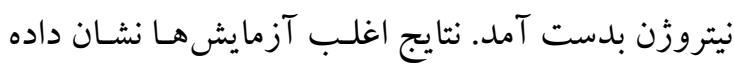

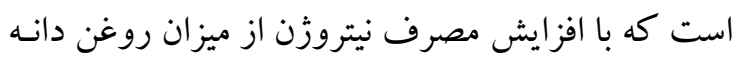

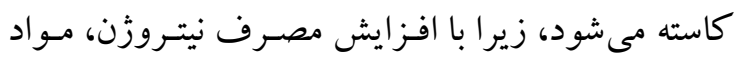
قابل دسترس براى سنتز اسيدهاى جرب كـاهش يافتـه و

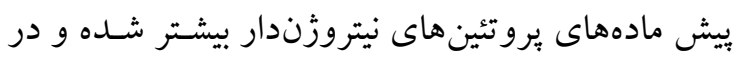

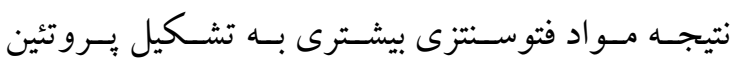




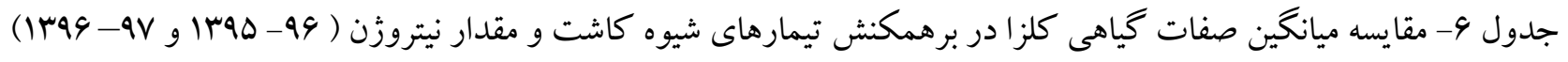

Table 6. Mean comparison of plant traits of rapeseed in interaction effect of planting method and nitrogen fertilizer treatments (2016-2018)

\begin{tabular}{|c|c|c|c|c|c|c|c|}
\hline Planting method & شيوه كاشت & Nitrigen rate $\left(\mathrm{kg} \cdot \mathrm{ha}^{-1}\right)$ & كود نيتروزن & $\begin{array}{c}\text { تعداد شاخه فرعى } \\
\text { No. Secondary branches }\end{array}$ & $\begin{array}{c}\text { خورجين در بو ته } \\
\text { Siliques.plant }{ }^{-1}\end{array}$ & $\begin{array}{c}\text { عملكرد دانه } \\
\text { Seed yield }\left({\left.\mathrm{kg} . h \mathrm{ha}^{-1}\right)}^{-}\right.\end{array}$ & $\begin{array}{c}\text { عملكرد روغن } \\
\text { Oil yield (kg.ha-1) }\end{array}$ \\
\hline \multirow[t]{4}{*}{ Direct seeding } & بذر كارى مستقيم & 0 & صفر & $3.49 \mathrm{f}$ & $76.3 \mathrm{~g}$ & $1493 \mathrm{~d}$ & $659 \mathrm{e}$ \\
\hline & & 100 & $1 .$. & $4.57 \mathrm{~d}$ & $122.2 \mathrm{e}$ & $3249 \mathrm{c}$ & $1391 d$ \\
\hline & & 200 & $r \cdot$. & $5.48 \mathrm{c}$ & $147.6 \mathrm{~d}$ & $3933 \mathrm{~b}$ & $1647 \mathrm{bc}$ \\
\hline & & 300 & $r .$. & $5.56 \mathrm{c}$ & $155.3 \mathrm{~d}$ & $3950 \mathrm{~b}$ & $1623 \mathrm{c}$ \\
\hline \multirow[t]{4}{*}{ Transplanting } & نشاكارى & 0 & صفر & $4.24 \mathrm{e}$ & $104.7 f$ & $1451 \mathrm{~d}$ & $645 \mathrm{e}$ \\
\hline & & 100 & $1 .$. & $5.67 \mathrm{c}$ & $193.5 \mathrm{c}$ & $3230 \mathrm{c}$ & $1401 d$ \\
\hline & & 200 & r.. & $6.68 b$ & $229.8 b$ & $4068 \mathrm{~b}$ & $1714 \mathrm{ab}$ \\
\hline & & 300 & r.. & $7.03 \mathrm{a}$ & $247.6 \mathrm{a}$ & $4235 \mathrm{a}$ & $1755 \mathrm{a}$ \\
\hline
\end{tabular}

Means in each column followed by similar letter(s) are not significantly different at 5\% probability level, using LSD test 


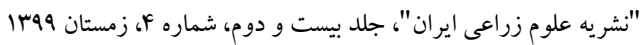

$$
\begin{aligned}
& \text { مناسب است. با اين وجـود، جهـت اطمينـان از بايـدارى }
\end{aligned}
$$

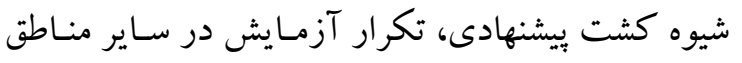

$$
\begin{aligned}
& \text { استان توصيه مىشود. } \\
& \text { سياسگز ارى }
\end{aligned}
$$

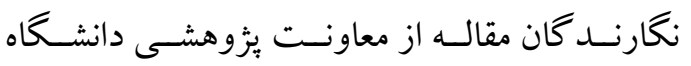

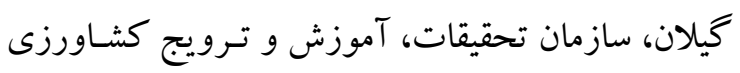

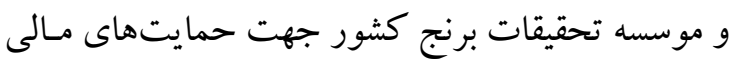

$$
\begin{aligned}
& \text { از اجراى اين تحقيق تشكر و قدردانى مىنمايند. }
\end{aligned}
$$

\section{References}

Alizadeh, M.R. and A. Allameh. 2015. Soil properties and crop yield under different tillage methods rapeseed cultivation in paddy fields. J. Agric. Sci. 60(1): 11-22.

Daneshmand, A.R., A.H. Shirani Rad, G. NourMohammadi, G.H. Zareei and J. Daneshian. 2008. Effect of irrigation regiems and nitrogen levels on seed yield and seed quality of two rapeseed (Brassica napus L.) cultivars. Iran. J. Crop Sci. 10(3): 244-261. (In Persian with English abstract).

Dehghani, M., M.J. Aghaee and S. Mohammadi Kia. 2015. Effect of cotton transplanting on its yield and water use efficiency. Iran. J. Soil WATER Res. 28(2): 307-314. (In Persian with English abstract).

Elewa, T.A., B.B. Mekki, B.A. Bakry and M.F. El-Kramany. 2014. Evaluation of some introduced canola (Brassica napus L.) varieties under different nitrogen fertilizer levels in newly reclaimed sandy soil. Middle East J. Sci. Res. 21(5): 746-755.

Fanadzo, M., S. Chiduza and P.N. Mnkeni. 2009. Comparative response of direct seeded and transplanted maize (Zea mays L.) to nitrogen fertilization at Zanyokwe irrigation scheme, Eastern Cape, South Africa. Afr. J. Agric. Res. 4(8): 689-694.

FAOSTAT. 2017. Statistical Database of the Food and Agriculture Organization of the United Nations.

Fooladivand, S., A. Aynehband and F. Naraki. 2009. Effects of tillage method, seed rate and microelement spraying time on grain yield and yield components of rapeseed (Brassica napus L.) in warm dryland condition. J. Food Agric. Environ. 7(3-4): 627- 633.

Gajri, P.R., V.K. Arora and S.S. Prihar. 2002. Tillage for sustainable cropping. Food Products Press, An imprint of The Haworth Press. New York, USA.

Hernan, S.R., E.E. Hernan, A.S. Guillermo and D. German. 2000. Evaluation of the presidedress soil nitrogen test for no-tillage maize fertilizer at planting. Agron. J. 92: 1176-1183.

Hosseinzadeh, M.H., M. Esfahani, M. Rabiee and B. Rabiei. 2008. Effect of row spacing on light interception, grain yield and growth indices of rapeseed (Brassica napus L.) cultivars as second crop 


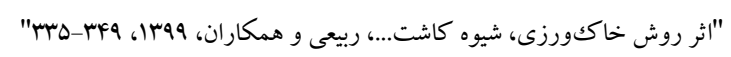

following rice. Iran. J. Crop Sci. 10(3): 281-302 (In Persian with English abstract).

Imaz, M.J., I. Virto, P. Bescansa, A. Enrique, O. Fernandez and D.L. Karlen. 2010. Soil quality indicator response to tillage and residue management on semi-arid Mediterranean cropland. Soil Till. Res. 107: 17-25.

Jafarnejad, A. and A.R. Rahnama. 2011. Investigation the effect of delay in sowing on yield of canola and nitrogen application efficiency. Iran. J. Soil Water Res. 25(3): 225-233. (In Persian with English abstract).

Karlen, D.L., C.A. Cambardella, J.L. Kovar and T.S. Colvin. 2013. Soil quality response to long-term tillage and crop rotation practices. Soil Till. Res. 133: 54-64.

Kazemeini, S.A., H. Hamzehzarghani and M. Edalat. 2010. The impact of nitrogen and organic matter on winter canola seed yield and yield components. Aust. J. Crop Sci. 4: 335-342.

Mirzapour, M.H., A.H. Khoshgoftarmanesh, M.H. Davoodi and A.H. Koochebaghi. 2014. Effect of different amounts of nitrogen on growth and yield of two canola cultivars (Brassica napus L.) in two saline soils. Iran. J. Soil Water Res. 28(1): 1-14. (In Persian with English abstract).

Mohammadi, Kh., K. NabiAllahi, M. Aghaalikhani and F. Khoormali. 2009. Study on the effect of different tillage methods on the soil physical properties, yield and yield components of rainfed wheat. Int. J. Plant Prod. 16(4): 77-91. (In Persian with English abstract).

Mousavian, S.N., S.A. Siadat, M.R. Moradi Telavat and S.H. Mousavi. 2013. Yields reaction, nitrogen uptake and canola qualitative attributes to nitrogen levels and previous plants. Int. J. Food Allied Sci. 2(18): 698-703.

Omidi, H., Z. Tahmasebi Sarvestani, A. Ghalavand and S.A.M. Modarres Sanavi. 2004. Evaluation of tillage systems and row distances on grain yield and oil content in two canola (Brassica napus L.) cultivars. Iran. J. Crop Sci.7 (2): 97-111. (In Persian with English abstarct).

Ozturk, O. 2010. Effects of source and rate of nitrogen fertilizer on yield, yield components and quality of winter rapeseed (Brassica napus L.). Chil. J. Agric. Res. 70(1): 132-141.

Rahnema, A. and A. Bakhshande. 2004. Effect of sowing dates and direct seeding and transplanting methods on agronomic characteristics and grain yield of canola under Ahvaz conditions. Iran. J. Crop Sci. 7(4): 324336. (In Persian with English abstract).

Rameeh, V. and M.B. Salimi. 2015. Effect of different nitrogen rates on phenology, plant height, yield components and seed yield of rapeseed (Brassica napus L.). J. Plant Prod. 2(1): 1-12. (In Persian with English abstract).

Rathke, G., W.O. Christen and W. Diepenbrock. 2005. Effect of nitrogen source and rate on productivity and quality of winter oilseed rape (Brassica napus L.) grown in different crop rotation. Field Crops Res. 94(2-3): $103-113$

Seed and Plant Improvement Institute. 2016. Rapeseed production guidelines in different climates of the country. Jihad-e-Agriculture Ministry. ARREO. (In Persian). 


$$
\text { "نشريه علوم زراعى ايران"، جلد بيست و دوم، شماره f، زمستان ج9ه| }
$$

Seyedi, R.S., H. Amirshekari, H. Omidi and M. Rabiee. 2018. Effect of ethephon application and harvesting date on yield, seed losses and oil percent of rapeseed. J. Plant Physiol. 39(10): 113-130. (In Persian with English abstract).

Taheri, E., A. Soleymani and H.R. Javanmard. 2012. The effect of different nitrogen levels on oil yield and harvest index of two spring rapeseed cultivars in Isfahan region. Int. J. Agric. Crop Sci. 4: 1496-1498.

Tahmasebi, G., S.A. Siadat, M.M. Pour Siabidi and R. Naseri. 2013. Effect of planting dates on seed yield and vegetative traits of rapeseed cultivars in Ilam region. J. Plant Physiol. 7(3): 241-258. (In Persian with English abstract).

Wang, Y. and X. Li. 2011. Study on nitrogen fertilizer effect and optimum fertilizer rate for transplanting and direct seeding rapeseed. Scientia Agricultura Sinica. 44(21): 4406-4414. 
"اثر روش خاككورزى، شيوه كاشت.... ربيعى و همكاران،

\title{
Effect of tillage system, planting method and nitrogen fertilizer rate on agronomic characteristics and seed yield of oilseed rape (Brassica napus L.) cv. Dalgan in Guilan, Iran
}

\section{Rabiee, M. ${ }^{1}$, M. Majidian², M.R. Alizadeh $^{3}$ and M. Kavoosi ${ }^{4}$}

\begin{abstract}
Rabiee, M., M. Majidian, M. R. Alizadeh and M. Kavoosi. 2020. Effect of tillage system, planting method and nitrogen fertilizer rates on agronomic characteristics and seed yield of oilseed rape (Brassica napus L.) cv. Dalgan in Guilan, Iran. Iranian Journal of Crop Sciences. 22(3): 335-349. (In Persian).
\end{abstract}

To study the effects of tillage system, planting method and of nitrogen fertilizer rate on the agronomic characteristics and seed yield of rapeseed (Brassica napus L.) Dalgan oilseed rape cultivar, as the second crop after rice, a split factorial experiment in complete randomized block design with three replications was carried out in two cropping seasons (2016-2018) at paddy fields of Rice Research Institute of Iran, Rasht, Iran. In this experiment, three tillage systems (conventional tillage, minimum tillage, and no-tillage) were considered as main plots and two planting methods (direct and transplanting) and four rates of nitrogen $(\mathrm{N})$ fertilizer $(0,100,200$ and $300 \mathrm{~kg} \cdot \mathrm{ha}^{-1}$ ) as factorial arrangement in sub plots. The results showed that conventional and minimum tillages in the transplanting method had the maximum seed yield (with the averages of 3458 and $3360 \mathrm{~kg} \cdot \mathrm{ha}^{-1}$, respectively). Transplanting method with $300 \mathrm{~kg} \cdot \mathrm{ha}^{-1}$ of nitrogen level had higher number of auxiliary branches per plant, number of siliques per plant, seed yield, and oil yield. Minimum tillage system with $200 \mathrm{~kg} \cdot \mathrm{ha}^{-1}$ of nitrogen with an average seed yield of $4144 \mathrm{~kg} \cdot \mathrm{ha}^{-1}$ had the highest seed yield. Based on the results of this experiment, minimum tillage system with $200 \mathrm{~kg} \cdot \mathrm{ha}^{-1}$ of nitrogen in both planting methods, direct seeding and transplanting, would be more suitable for oilseed rape production in Guilan region.

Key words: Direct seeding, Minimum tillage, Nitrogen fertilizer, Rapeseed and Transplanting. 